\title{
O ensino de Terapia Ocupacional na clínica das dependências: Uma experiência na liga acadêmica de farmacodependências (PROAD - UNIFESP)
}

\author{
Marina Bianco Perrone, Ana Paula Malachowski Levi Bianchini, \\ Thiago Marques Fidalgo, Dartiu Xavier da Silveira
}

Programa de Orientação e Atendimento a Dependentes (PROAD), Departamento de Psiquiatria, Universidade Federal de São Paulo - UNIFESP, São Paulo, SP, Brasil

\begin{abstract}
Resumo: Objetiva-se discutir o ensino de Terapia Ocupacional (TO) no contexto da dependência química com alunos de graduação. Visando debater sobre a experiência da prática multidisciplinar supervisionada durante o trajeto de formação acadêmica, apresenta-se a Liga Acadêmica de Farmacodependências (LFD) como espaço para compreensão do fenômeno da dependência e da construção da clínica. Foi realizado um estudo qualitativo, de caráter observacional, no qual foi realizada a análise de conteúdo das discussões realizadas entre os preceptores e os 25 alunos de diferentes cursos (TO, Psicologia, Enfermagem e Medicina) que compõem a LFD, vinculada ao PROAD (Programa de Orientação e Atendimento a Dependentes) da Universidade Federal de São Paulo. Foram observadas articulações acerca da construção do raciocínio clínico em TO, assim como sobre a constituição do olhar do aluno enquanto profissional membro de uma equipe multidisciplinar. A experiência da construção da especificidade da TO, somada à articulação de diferentes olhares na supervisão coletiva, favoreceu a construção de uma compreensão ampliada sobre os sujeitos atendidos na LFD. As discussões de caso coletivas permitem um diálogo multidisciplinar que vai constituindo a identidade dos alunos enquanto profissionais da saúde que se posicionam em uma equipe de raciocínio coeso. Percebeu-se que o ensino de TO, no contexto de uma liga multiprofissional, inserida em um programa de atenção a pessoas com problemas relacionadas ao uso, abuso e/ou dependência de substâncias, tem sido uma experiência de construção contínua de um espaço que visa sustentar e dialogar sobre questões da especificidade da profissão e da sua inserção em equipe.
\end{abstract}

Palavras-chave: Terapia Ocupacional, Ensino, Saúde Mental, Transtornos Relacionados ao Uso de Substâncias.

\section{Teaching Occupational Therapy on the Addiction Field - An experience in a multidisciplinary context with undergraduate students}

\begin{abstract}
This article intends to discuss the teaching of Occupational Therapy (OT) in the context of substance abuse to undergraduate students. Aiming to debate the experience of multidisciplinary supervised practice during the course of academic studies, it presents the Academic League on Drug Dependence - LFD as a space for understanding the phenomenon of addiction and the construction of practice in this area. A qualitative observational study was carried out on the analysis of discussion between tutors and 25 undergraduate students from different courses (OT, psychology, nursing, and medicine) that comprise the LFD, which is associated with the Program of Treatment and Guidance to Drug Addicts - PROAD of the Federal University of São Paulo - UNIFESP. We observed articulations about the construction of clinical reasoning in the OT area and the constitution of the students' perceptions while professionals participating in a multidisciplinary team. It was possible to observe that the experience of the specificity of OT and collective supervision, which, in turn, enables the articulation, favored the construction of an expended comprehension of the subjects treated in the LFD. In this sense, the collective discussion of cases
\end{abstract}

Autor para correspondência: Marina Bianco Perrone, Programa de Orientação e Atendimento a Dependentes - PROAD, Av. Prof. Ascendino Reis 763, Vila Clementino, CEP 040027-000, São Paulo, SP, Brasil, e-mail: maperrone90@ gmail.com

Recebido em 30/8/2013; Revisão em 21/2/2014; Aceito em 4/5/2014. 
allowed multidisciplinary dialogue that will constitute the identity of students as health professionals who position themselves in a coherent team. It was perceived that the teaching of OT, in the context of a multiprofessional league, inserted in a program of care for people with problems related to substance use, abuse and/or dependence, has been an experience of a continuous construction of a space that supports and dialogues on issues of the specificity of profession, and its inclusion in this team.

Keywords: Occupational Therapy, Teaching, Mental Health, Substance-related Disorders.

\section{Introdução}

Durante o processo de formação profissional busca-se articular a teoria com a prática da profissão. Essa fundamentação, em Terapia Ocupacional, capacita os profissionais para disponibilizarem à população atendida elementos que possibilitem o alcance de autonomia e funcionalidade no contexto da saúde física, mental e/ou social (MARINS; EMMEL, 2011). Isso porque o enfoque da profissão tem a qualidade de vida como fator de intervenção e reabilitação (MARINS; EMMEL, 2011). Nesse sentido, a formação prática, concomitantemente ao estudo da teoria, é bastante importante durante o ensino dessa profissão. Além disso, é importante não deixar de considerar a necessidade de o aluno ter disposição pessoal para compreender informaçóes, assim como para a apresentação dos conteúdos de forma logicamente significativa (NAJJAR; ALVES, 2010). Somente dessa forma pode-se ter uma formação de qualidade em Terapia Ocupacional.

Alguns cursos de graduação em Terapia Ocupacional utilizam metodologias de ensino baseadas em problemas. Em estudo sobre um desses cursos, Arruda et al. (2012) ressaltam que por parte dos alunos em formação é importante a aquisição da autonomia e independência na busca do próprio conhecimento, bem como o desenvolvimento da capacidade reflexiva e do raciocínio clínico. A constituição da formação do Terapeuta Ocupacional, com experiências de problematização de situações a partir da construção de diálogos entre profissionais e alunos, é desafiadora para os graduandos, no papel de investigadores críticos, pois associa o problema disparador da discussão a outros problemas que irão disparar novas discussões em um processo contínuo (NAJJAR; ALVES, 2010). Quanto aos conteúdos da formação, também é destacado na literatura por Marins e Emmel (2011) o favorecimento da articulação em equipes multiprofissionais. Tal competência faz-se importante no cenário de atenção integrada à saúde mental, na diversidade de compreensôes e coesão de açôes de equipes multidisciplinares.

O grande valor da atuação em equipe multidisciplinar está no fato de ela proporcionar o encontro dos diferentes campos de conhecimento e possibilitar a construção coletiva de estratégias de intervenção (COUTINHO; SANTOS; PASSOS, 2012). Ao pensar os profissionais de saúde como sujeitos com competência para agirem frente a situações pertinentes à sua área de atuação, é necessário considerar que tal conhecimento é derivado de sua constituição no processo de formação. Assim se faz necessária uma abordagem dialética que, segundo Barba et al. (2012), articule teoria e prática, educação e trabalho, distintas áreas de conhecimento e as dimensóes diversas envolvidas num processo de formação.

Este trabalho tem como objetivo discutir o ensino de Terapia Ocupacional a alunos de graduação inseridos em um serviço de atenção a pessoas com problemas relacionados ao uso, abuso e/ou dependência de substâncias. Visa discutir essa experiência na prática específica da Terapia Ocupacional e em seus diálogos multidisciplinares. Compreensôes quanto à formação do terapeuta ocupacional, à construção de raciocínio específico desta clínica e ao diálogo com as outras profissões da saúde são abordadas a partir dessa experiência.

\section{Método}

\subsection{Setting}

A Liga Acadêmica de Farmacodependências (LFD) é vinculada ao Programa de Orientação e Atendimento a Dependentes (PROAD) do Departamento de Psiquiatria da Escola Paulista de Medicina da Universidade Federal de São Paulo. Desde sua fundação, em 2004, a LFD é um espaço semanal no qual alunos de graduação de Enfermagem, Medicina, Psicologia e Terapia Ocupacional e os respectivos preceptores de cada área participam de discussóes sobre os transtornos relacionados ao uso de substâncias e sobre saúde mental. São abordados conceitos de saúde e, também, aspectos sociais, políticos e culturais. Esses debates favorecem a compreensão dos assuntos discutidos não apenas como situaçóes teóricas mas como fenômenos que podem ser compreendidos de diversas maneiras. 
Além dessas atividades, os alunos membros da LFD realizam atendimentos longitudinais em sua área de formação, sempre com a supervisão de um profissional já graduado e com experiência na área. Os atendimentos de Terapia Ocupacional são sempre individuais e são discutidos em supervisão específica semanal. Esse espaço de supervisão visa explorar a compreensão de cada relação terapêutica, a construção do raciocínio clínico, os aspectos transferenciais e contratransferenciais. Também são discutidas as diferentes fundamentações teóricas e aspectos conceituais de diferentes referenciais teóricos, as questôes sobre o trabalho multiprofissional e a inserção do terapeuta ocupacional na equipe e na rede de saúde, bem como questóes relacionadas às políticas públicas sobre drogas e sua interferência na prática clínica.

Semanalmente também ocorre supervisão multiprofissional, com a participação de todos os alunos e preceptores que compóem a LFD. Nesta são discutidos os atendimentos de cada um dos pacientes, abrangendo os acompanhamentos que cada um deles recebe e as questóes pertinentes a eles, como a compreensão clínica, psiquiátrica, psicodinâmica e social, a evolução em cada um dos atendimentos específicos, as mobilizaçôes frente a eles, os encaminhamentos necessários e a articulação com a teoria, para assim construir a direção das intervençôes.

\subsection{Delineamento do estudo}

Trata-se de um estudo qualitativo, que relata criticamente uma experiência de ensino desenvolvida na Liga Acadêmica de Farmacodependências. Foi feita análise de conteúdo das discussóes realizadas entre os preceptores e os alunos da LFD. Nesse caso, utilizou-se um conjunto de técnicas de pesquisa cujo objetivo é a busca do sentido ou dos sentidos de um documento (MINAYO, 2011). A partir da seleção de informaçôes coletadas nessas discussôes, construiu-se um novo documento, com um novo sentido (PENAA; MORILLO, 2007). Trata-se de técnica que vem sendo utilizada por outros autores (FIDALGO, 2014) com o objetivo de captar a riqueza de experiências humanas que náo podem ser medidas por estudos qualitativos mas que, por seu caráter extremamente dinâmico, também não caberiam no método qualitativo clássico, especialmente porque os pesquisadores são parte do processo. Dessa forma, a pesquisa é uma prática produtora de realidades e não desveladora de uma realidade já dada (MINAYO, 2011).

\subsection{População}

Participaram do estudo todos os alunos que compóem a liga, sendo: cinco alunos de graduação em Terapia Ocupacional, uma aluna de graduação em Psicologia, quatro alunas de graduação em Enfermagem e 15 alunos de graduação em Medicina.

\subsection{Coleta e análise de dados}

A preceptoria, composta por dois psiquiatras, uma psicóloga, duas terapeutas ocupacionais e uma enfermeira, se organizou de maneira a trabalhar com os alunos os assuntos emergentes dos casos discutidos, durante as discussóes específicas, as multiprofissionais e as atividades teóricas. Tais discussões foram transcritas semanalmente na ata $\mathrm{da}$ reunião e, em seguida, discutidas novamente, pelos preceptores, quinzenalmente, visando favorecer a composição multiprofissional, o desenvolvimento do raciocínio clínico específico e da autonomia dos alunos.

\section{Resultados e discussão}

Nos espaços de supervisão da LFD, os alunos podem trazer suas percepçóes acerca de cada caso atendido, suas impressóes decorrentes do contato com o sujeito durante o atendimento. A partir da facilitação dos preceptores, percebe-se que vão sendo construídas discussóes, não apenas para compor condutas terapêuticas mas para estruturar leituras dinâmicas acerca do sujeito atendido, na medida em que os alunos se expressam em um espaço no qual sua compreensão pode ser articulada com a dos demais estudantes, assim como com as diversas teorias. É notável que a estimulação dos alunos pelos preceptores das várias áreas (e não só da Terapia Ocupacional), para a construção do raciocínio clínico, permite que essa composição considere a multidisciplinaridade, chegando a um olhar complexo que abrange diversas perspectivas.

Durante as reuniôes é possível perceber que essa construção do tratamento de maneira integrada e dialética ajuda os alunos a se aproximarem das especificidades de sua área para, em seguida, compartilharem sua compreensão com todo o grupo. $\mathrm{Na}$ LFD, esse movimento de alternância entre o específico e o geral propicia que o olhar se enriqueça e que o aluno, aos poucos, se aproprie do seu papel dentro da equipe multiprofissional. Nesse sentido, percebe-se a importância do espaço de supervisão como espaço de promoção de interligaçáo entre os atendimentos, compreendidos como unidades de ação frente ao paciente (BLOISE, 1993). Ao longo de todo 
o trabalho da LFD, a supervisão é, também, tratada como instrumento para identificar as dificuldades da equipe e lidar com elas de forma criativa.

$\mathrm{Na}$ experiência da LFD, a compreensão multidisciplinar favorece a atenção integrada, assim como compóe o raciocínio do terapeuta ocupacional. Tedesco (2007) compreende que apesar de não traduzirem a integralidade para os procedimentos específicos de Terapia Ocupacional, os procedimentos interdisciplinares trazem recursos e contribuiçóes importantes. Sendo assim, o entendimento de cada caso pelo aluno de Terapia Ocupacional no contexto da LFD vai sendo construído entre a articulação das discussóes da equipe com aquilo que é percebido nos atendimentos específicos, para então construir-se um raciocínio clínico auxiliado por um contorno que ocorre na supervisão dessa área.

Nesse espaço percebe-se que a utilização frequente de publicações sobre abordagens psicodinâmicas em Terapia Ocupacional tem sido importante base do ensino do pensamento dessa clínica no que diz respeito à compreensão dos sujeitos e dos procedimentos durante os atendimentos. Nesse sentido, favorecer o entendimento sobre como cada encontro é construído no setting pela tríade sujeito-terapeuta-atividades propicia que o aluno vá percebendo em cada relaçáo dinâmica o potencial transformador e de produção e reprodução na vida cotidiana. Para nortear a construçáo desse raciocínio, parte-se do pressuposto de que dentro da situação terapêutica é construída uma história relacional que, segundo Tedesco (2007), potencializa uma relação saudável consigo, com o outro e com o social, através de estratégias de uso do fazer como encontro.

Durante as supervisóes específicas, busca-se favorecer a compreensão da apresentação de cada sujeito para a relaçấo. No contexto estudado, trata-se do contato com pessoas que procuraram o PROAD por problemáticas relacionadas ao uso de substâncias, aspecto que é considerado parte da condição desse sujeito. Além disso, busca-se compreender outras questôes individuais, assim como a situaçáo de cada um dos sujeitos, visto que o tratamento propóe-se responder às necessidades deles, olhando para aquilo que é singular em cada um (KARAGUILLA, 2010, p. 151).

Nessa lógica, as supervisões específicas de Terapia Ocupacional na LFD favorecem e sustentam uma contínua compreensão do caso, a partir de um diagnóstico situacional que norteia a forma de o terapeuta apresentar-se para essa relação e as terapias ocupacionais que cabem frente a esse sujeito, nesse momento. Constrói-se com os alunos uma atuação embasada na compreensão de Oliveinstein (1985), em O Destino do Toxicômano, obra que sustenta que é o encontro que pode criar outra completude, a partir da falta. $\mathrm{O}$ autor refere-se ao processo terapêutico compreendendo que o terapeuta é percebido como um outro que se oferece como em um jogo, na medida em que incorpora a ausência e a falta, e também se torna o ser mais seguro e perene a quem o paciente em situação de dependência já deu importância. Segundo ele, nessa relação, a demonstração da toxicomania deixa de ser um náo sentido e surge uma tentativa repetida na busca de uma bipolaridade criadora de sentido.

Assim, durante a discussão dos atendimentos é possível que os fazeres do sujeito frente às situações sejam constantemente observados, buscando entender como cada um dos indivíduos faz uso de seus recursos na relação terapêutica e nos demais contextos de sua vida. "O que importa realmente é o modo de utilização desse movimento na relação e não o movimento interno que a cria [...]" (OLIVEINSTEIN, 1985, p. 54). A partir da leitura sobre os movimentos relacionais é possível estabelecer uma comunicação entre terapeuta e paciente, o que Benetton (1992) denomina código secreto. Segundo a autora, essa é uma linguagem particular, instruída nessa e para essa relação, sendo um fio condutor significante para a atuação dos atores.

Nesse sentido, as discussões do raciocínio clínico em supervisão partem dessas percepçóes da dinâmica do sujeito e desse diálogo próprio da relaçáo terapêutica para, assim, construir uma compreensão tanto do estado do indivíduo naquele momento, e das particularidades do caso, como das maneiras de intervir para conduzir o sujeito a uma relação de experimentação de liberdade na qual seja possível proporcionar a possibilidade da contratualidade e experienciar tomar posse de seus fazeres.

Segundo Karaguilla (2010), o processo de Terapia Ocupacional é permeado pela compreensão do ser humano como um ser capaz de fazer e que, perante a sociedade, busca a comunicação entre sua singularidade e a realidade compartilhada que pode, então, reconhecê-lo. A autora compreende que a terapia ocupacional procura favorecer maneiras inéditas, criativas de o paciente fazer suas atividades. Esse posicionamento do terapeuta frente ao caso só é possível a partir da percepção do indivíduo como alguém detentor de suas escolhas. No contexto da LFD, essa compreensão vai sendo construída no decorrer das supervisōes específicas, a partir da narrativa dos atendimentos, da observação da mobilização de cada aluno frente às situações vivenciadas, da escuta dos demais processos terapêuticos, da leitura multidisciplinar e da articulação com a teoria, visando compor um caminho para a construção do raciocínio clínico. Consideram-se tais leituras como extremamente 
importantes para que a relaçáo de caráter terapêutico se estabeleça a partir do pressuposto de um refinamento do olhar, do sentir, do perceber e do compreender, que vai sendo esclarecido e balizado pelo terapeuta ocupacional supervisor da LFD e pelo grupo de alunos que está atuando em Terapia Ocupacional.

Por isso, nesse contexto de ensino, dentre os aspectos citados para a composição da formação do aluno, a questáo transferencial é bastante abordada, sendo tratada de forma cuidadosa e com grande aprofundamento. Tal fenômeno é considerado não só fundamental, mas também visto como inerente à aproximação entre terapeuta e paciente nos processos de Terapia Ocupacional, à medida que as situações são vivenciadas nesse setting. A partir disso, torna-se fundamental incluir na formação desse profissional a conexáo com os fenômenos transferenciais e contratransferenciais. Partindo-se do princípio descrito por Benetton no Método da Terapia Ocupacional Dinâmica, Malachowski (2010) diz que a transferência, após ser reconhecida, pode ou não ser trabalhada na relação terapeuta-paciente. Nessa compreensão, Malachowski (2010) refere que a transferência é trabalhada na mobilização do terapeuta através do seu sentir, conseguindo sustentar essa relação dentro do setting. Nesse sentido, em supervisão são focadas as mobilizaçôes transferenciais e contratransferenciais vivenciadas dentro do setting pelos alunos, permitindo que esse espaço seja um espaço para falar não só do outro mas também de si. Dessa forma, as supervisôes da LFD são organizadas buscando-se possibilitar ao aluno o contato com questôes que emergem a partir do encontro terapêutico. $\mathrm{O}$ trabalho do supervisor inclui auxiliar o aluno a reconhecê-las para, entáo, construir uma maneira de manejá-las durante o atendimento, a fim de instrumentalizá-lo a favor dos objetivos traçados para cada sujeito atendido.

À medida que a compreensão sobre o sujeito atendido e sobre o raciocínio clínico em Terapia Ocupacional vão acontecendo nesse espaço protegido, é possível observar que os alunos vão se apropriando de sua prática e conseguindo falar sobre ela em diálogos com a equipe, durante a supervisão multiprofissional. Cumpre notar que ao chegarem na LFD a quase totalidade dos alunos de Medicina, Psicologia e Enfermagem não sabe determinar qual a função do terapeuta ocupacional dentro da equipe de saúde. Percebe-se que, dentro da LFD, conforme vai ocorrendo a exposição às discussóes de casos com supervisão do terapeuta ocupacional e de alunos do curso, pouco a pouco os demais alunos entram em contato com as técnicas e particularidades dessa profissão. Os alunos de outros cursos não dominam a especificidade da Terapia Ocupacional, fato que não é esperado pelos preceptores. Mas sim vão se aproximando do diálogo com essa prática e também vão trazendo para sua intervenção um olhar que considera a relaçấo profissional-paciente táo cara aos profissionais de Terapia Ocupacional. Nota-se, então, uma evolução nos alunos frente às articulaçóes em equipe e um reconhecimento do papel do terapeuta ocupacional. Percebe-se que essa prática passa a ser considerada pelos demais alunos, que passam a realizar discussóes pertinentes sobre a área, resultando em encaminhamentos clinicamente pertinentes vindos dos alunos da Medicina e articulações cada vez mais ricas frente aos casos.

É possível observar que o olhar voltado para o fazer humano, específico da Terapia Ocupacional, possibilita que a equipe, no contexto da $\mathrm{LFD}$, valorize a compreensão do sujeito também como um ser dinâmico, que interage com o mundo à sua volta. Esse olhar acerca do sujeito tem permitido que os demais estudantes, especialmente os de Medicina, foquem não apenas na doença mas também aprendam a considerar os aspectos saudáveis do paciente, assim como a compreender suas potencialidades, ambas aquisiçôes com impacto em seu cotidiano.

\subsection{A LFD como caminho para formação do Terapeuta Ocupacional na clínica das dependências}

A experiência da construção da especificidade da Terapia Ocupacional, somada à supervisão coletiva que, por sua vez, permite a articulação entre os olhares, tem favorecido a construção de uma compreensão ampliada sobre os sujeitos atendidos na LFD. Dessa maneira, os profissionais em formação deixam de lidar com um paciente e passam a se relacionar com um sujeito ativo em seu tratamento e detentor de seus desejos. Assim, o papel do supervisor na LFD é tanto o de facilitar as trocas entre os alunos dos diferentes cursos quanto o de promover reflexáo quanto ao papel de cada um e do outro, compreendendo, assim, suas funçóes enquanto técnicos de uma equipe que dialoga.

Nesse contexto, a Terapia Ocupacional tem uma contribuição importante na construçáo da compreensão da saúde mental do sujeito, de seu funcionamento e da interferência desses aspectos em seu cotidiano. Nesse estágio de Terapia Ocupacional na LFD, as discussôes de caso coletivas permitem um diálogo multidisciplinar que vai constituindo a identidade dos alunos enquanto profissionais da saúde que se posicionam em uma equipe de raciocínio coeso. 
Enquanto isso, a supervisão específica em Terapia Ocupacional, com foco na abordagem psicodinâmica, possibilita a compreensão do sujeito como um ser que interage com o mundo à sua volta e o reproduz no processo terapêutico. As discussóes dos casos, permeadas pela relação triádica (sujeito-terapeuta-atividades), permitem a percepção de aspectos específicos da profissão, sua prática em saúde mental e a articulação com as demais especificidades envolvidas, favorecendo a percepção do sujeito em questão e da construção da intervenção nessa especificidade. Nesse sentido são construídas estratégias para o foco do tratamento na transformação da relação entre o indivíduo e o mundo, de forma que essa não seja mais intermediada pela droga, mas que o sujeito possa encontrar outras formas de existir.

O ensino de Terapia Ocupacional, no contexto de uma liga multiprofissional, inserida em um programa de atenção a pessoas com problemas relacionadas ao uso, abuso e/ou dependência de substâncias, tem sido uma experiência de construção contínua de um espaço que visa sustentar e dialogar sobre questóes da especificidade da profissão, da inserção dessa em uma equipe e do momento de início da formação. A LFD, como espaço de extensão durante a graduação, construído a partir de prática de Terapia Ocupacional e de atenção multiprofissional, ambas supervisionadas em seus respectivos momentos, permite que o aluno de Terapia Ocupacional vivencie, de forma cuidada, seu processo de construção de formaçáa profissional nessa área de atuação.

\section{Referências}

ARRUDA, A. E. et al. Formação e pesquisa em saúde: relato de experiência na atenção primária à saúde. Revista Brasileira de Educação Médica, Belo Horizonte, v. 36, n. 1, p. 102-110, 2012. Suplemento 1.

BARBA, P. C. S. D. et al. Formação inovadora em Terapia Ocupacional. Revista Interface: Comunicação, Saúde e Educação, Botucatu, v. 16, n. 42, p. 829-842, 2012.

BENETTON, M. J. Na articulação entre o "falar" e o "fazer": a construçấo da historicidade na psicose. Revista de Terapia Ocupacional da USP, Sáo Paulo, v. 3, n. 1-2, p. 4-7, 1992.

BLOISE, P. V. Crise e multidisciplinaridade. Boletim de Psiquiatria, Sáo Paulo, v. 26, n. 1-2, p. 23-27, 1993.

COUTINHO, I. J.; SANTOS, K. R.; PASSOS, A. J. M. M. Novos tempos, novas práticas: os desafios na formaçáo dos profissionais de terapia ocupacional. Revista Acta Fisiátrica, São Paulo, v. 19, n. 3, p. 138-41, 2012. http:// dx.doi.org/10.5935/0104-7795.20120021

FIDALGO, T. O (Trans) Formar-se em grupo: trilhando caminhos entre um espaço de arte e cultura e as mulheres da regiāo Noroeste de Santos-SP. 2014. 52 f. Trabalho de Conclusão de Curso de Graduação em Terapia Ocupacional -Universidade Federal de São Paulo, Santos, 2014.

KARAGUILLA, M. D. A experiência criativa no tratamento de dependentes de substâncias psicoativas: a intervenção da terapia ocupacional. 2010. 183 f. Dissertação (Mestrado)Escola Paulista de Medicina, Universidade Federal de São Paulo, São Paulo, 2013.

MALACHOWSKI, A. P. O fenômeno da transferência e $o$ setting de terapia ocupacional. 2010. 26 f. Monografia de Pós Graduação - Programa de Especialização em Terapia Ocupacional em Saúde Mental, Escola Paulista de Medicina, Universidade Federal de Sáo Paulo, São Paulo, 2010.

MARINS, S. C. F.; EMMEL, M. L. G. Formaçáo do terapeuta ocupacional: acessibilidade e tecnologias. Cadernos de Terapia Ocupacional da UFSCar, São Carlos, v. 19, n. 1, p. 37-52, 2011.

MINAYO, M. C. S. (Org.). Pesquisa social: teoria, método e criatividade. 30. ed. Petrópolis: Vozes, 2011.

NAJJAR, E. C. A.; ALVES, L. M. S. A. Atividades de pesquisa na graduação: percepção dos alunos do curso de Terapia Ocupacional da Universidade do Estado do Pará. Cadernos de Educação, Pelotas, v. 36. p. 293-318, 2010.

PEÑA, V. T. ; MORILLO, J. La complejidad de análisis documental. Información, Cultura y Sociedad, Buenos Aires, n. 16, p. 55-81, 2007.

OLIVEINSTEIN, C. O destino do toxicômano. São Paulo: Almed, 1985.

TEDESCO, S. A. Diálogos da terapia ocupacional e a psicanálise: terapia ocupacional psicodinâmica. In: CAVALCANTI, A.; GALVÃO, C. Terapia ocupacional: fundamentação \& prática. Rio de Janeiro: Guanabara Koogan, 2007. p. 156-161.

\section{Contribuição dos Autores}

MBP, APMLB e TMF foram responsáveis pela realizaçấo da intervenção, pelas supervisões e pela coleta dos dados, além da elaboração da primeira versão do artigo. DXS orientou no desenho metodológico e na elaboração da intervenção, além de ter revisado a primeira versão do artigo. Todos os autores revisaram a versão final do artigo. 